\title{
A PRELIMINARY STUDY OF THE TRACHEAL SYSTEM OF THE MATURE LARVA OF BLEPHARIPA SCUTELLATA R-DESVOIDY. ${ }^{1}$
}

By Milton F. CRowell.

Blepharipa scutellata R-Desvoidy is one of the imported parasites of the gypsy moth, Porthetria dispar (L). The individuals studied emerged from pupae of the moth collected in July 1929, in southern New Hampshire. I had but four larvae and one puparium to examine, hence the study of this insect is by no means complete, and note can be made of only the more obvious features.

The larva of this insect has the amphipneustic type of respiratory system (Palmen 1877 , DeGuyse 1926) characterized by one pair of functional spiracles on the prothorax and from one to three pairs of functional spiracles at the end of the body. This is considered to be a secondary, physiological type, (DeGuyse 1926), but the larvæ of muscoid flies possess a higher type in a rudimentary, or nascent state.

\section{The Spiracles.}

The anterior pair of spiracles was not observed in detail. Their general position was noted in a study made of the tracheae visible through the integument at the cephalic end of the body. The main tracheal trunk appeared to bend upward and join the body wall near the posterior margin of the prothorax. Since Snodgrass (1924) found the prothoracic larval spiracles of Rhagoletis pomonella Walsh (the apple maggot) to be located in a position similar to these

1Contributions from the Entomological Laboratory of the Bussey Institution, Harvard University, No. 321. 
observed tracheal endings, the conclusion that these endings indicate the position of the spiracles seems warranted. (Fig. 1).

At the posterior end of the body are two fairly heavy chitinous rings marking the edges of the spiracles. In each of these, covering the spiracle openings, are chitinous plates which vary in their thickness. I was unable to see any openings through these plates. Greene, describing puparia of muscoid flies, (1921), states that "each plate has two or more openings for respiration, and these openings are called "slits;" Snodgrass (1924) describes the openings in the stigmatic plates of Rhagoletis.

Just beneath the stigmatic plate is the stigmatic chamber. The walls of this chamber are slightly thicker than the tracheal walls to which they are joined, and they are somewhat pigmented. Upon drying a reddish, rusty-looking deposit appeared on the walls and upon the interior surface of the stigmatic plate.

No lateral spiracles are observable on the larva.

Parkard (1874) in a short table of spiracular positions says that the larvae of Cecidomyiidae have nine pairs; one prothoracic, and eight abdominal, and that Muscidae have two pairs, one prothoracic, and one on the ninth abdominal segment. Further (1898), he says that the number of pairs varies in larval Diptera in adaptation to their varied modes of life.

Pratt (1897) figures an embryo of Melophagus ovinus (Linn) with a row of ten small circles inside of each of which is a smaller circle, which he designates as "Tracheal invaginations." Williams (1910) states that the larva of Cecidomyia resinicoloides Williams (Cecidomyiidae) has nine pairs of spiracles, "one on the first thoracic segment and one each on segments 4-11."

Snodgrass (1924) says that eight pairs of spiracles appear on the puparium of Rhagoletis, and he cites various authors to the effect that the lateral spiracles in larvae of the higher Diptera are present as imaginal discs.

It would appear, therefore, that in the higher Diptera the lateral spiracles are not absent, but remain in an undeveloped state until they take part in the formation of the 
peripneustic system of the adult. Palmen (1877) describes the removal of the larval tracheal lining through the rudimentary spiracles of Ephemerida and Trichoptera. The rudimentary second thoracic spiracle of Pyrausta nubilalis Hubn. (European corn borer: Lepidoptera) functions in the removal of the tracheal linings from the body at pupation. Snodgrass (1924) says that the lateral spiracles of the puparium of Rhagoletis are opened in the pupal stage by the shedding of the tracheal linings.

\section{The Longitudinal Trunks.}

On each side of the body is a large tracheal trunk. These are very large at their attachment to the walls of the stigmal chambers, and they taper to the anterior end of the body, where they divide into several smaller branches. Besides a gradual taper, these trunks taper abruptly at several places, and have somewhat the aspect of a telescope.

These trunks represent the dorsal longitudinal trunks (Dt fig. 2.), which, in the Trichoptera larvae are very much smaller than the ventral trunks, and which are apparently present only in the thorax of larval Lepidoptera.

The ventral longitudinal trunks (Vt fig. 2) which, according to Snodgrass (1924), send branches to the rudimentary spirales in Rhagoletis, and which are connected with the open spiracles in Cecidomyia (Williams 1910), appear in Blepharipa as anastomosing branches from the large dorsal trunks.

The dorsal trunks lie within the body cavity and are not crossed by muscles, as are the longitudinal trunks of the lepidopterous larvae. The ventral trunk is crossed by a muscle in the first abdominal segment ( $\mathrm{m} 1$ fig. 2.), and further investigation may show this condition present in the other body segments.

Transverse Tracheæ.

Snodgrass (1924) states that in Rhagoletis the dorsal trunks are connected by a dorsal commissure in all segments 
but the first; the first and the last being larger than the others, and going straight across. Williams (1910) figures and describes dorsal transverse tracheae in segments four to nine in Cecidomyia.

In Blepharipa I found, in the anterior part of the body, three transverse tracheae. The first springs from a branch of the dorsal trunk near the point of its division into several branches mentioned above. The origin of this branch lies beneath the protractor muscles of the pharynx, and the trachea bends around these muscles and crosses them, and the posterior part of the pharynx. No branches arise from it.

Rising from the opposite side of the dorsal trunk, apparantly at about the same place as the branch from which the transverse branch described above arises, is a branch which divides into three parts. The termination of the anterior branch I do not know. The middle branch runs diagonally backward above the duct of the salivary gland (sg fig. 2) and above the ganglia and meets a branch from the opposite side arising from a similar position, and having a similar path. This transverse commissure may send two branches backward to the ganglia. In one specimen examined it apparently did so, and in another it apparently did not. The third branch also runs diagonally backward, and apparantly supplies the ganglia (br fig. 2).

Arising from a point slightly behind one opposite the middle of the ganglia is another trachea which meets a corresponding branch from the opposite side, making the third of the transverse tracheae mentioned above. This seems a short branch forward from its junction point.

Other transverse tracheae are probably present.

\section{Tracheæ to the Nervous System.}

At about the line between the third thoracic and first abdominal segments, probably lying in the metathorax, a branch springs from the dorsal trunk and runs forward (1 fig. 2). Just anterior to its junction with the dorsal trunk a branch springs from it and runs beneath it toward the middle of the body. This branch shortly divides into six 
branches. The anterior one goes to the salivary gland. The next three run to the ganglia, and the posterior two supply fat bodies ( $\mathrm{fb}$ fig. 2). The three tracheal branches here mentioned, together with the branches described in the former section on transverse tracheae, appear to be all of the branches to the "brain."

The ventral ganglionic mass (g figs. 2,3), a large appendage of the brain lying ventral to the alimentary tract, receives its tracheae from branches from the ventral tracheal trunks (Vt fig. 3).

As far as I can determine from my notes the first ventral trachea to the abdominal central nervous system arises in

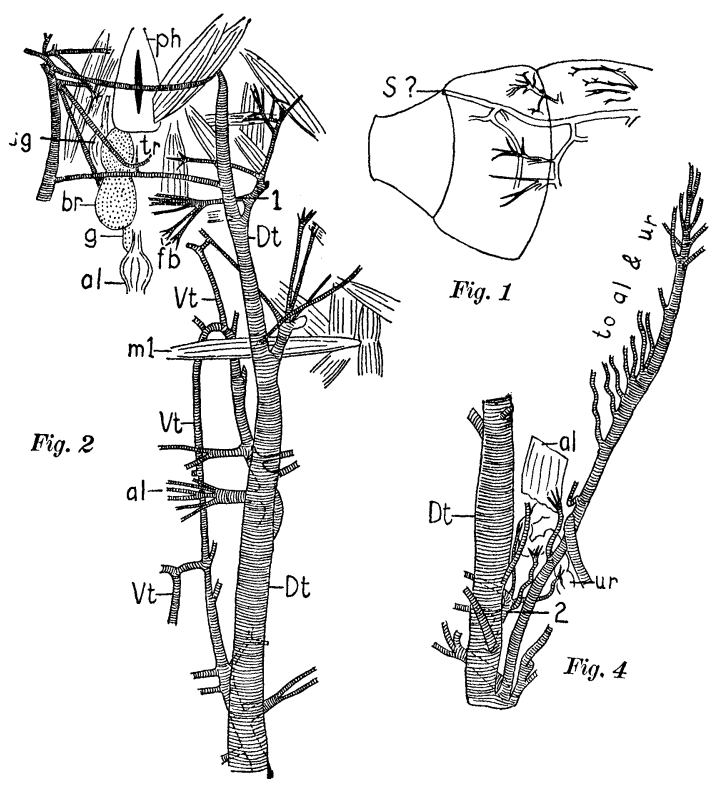

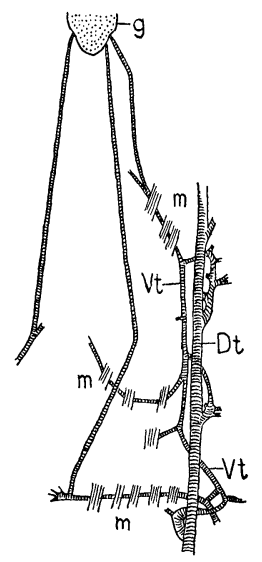

Fig. 3

Fig. 1. Sketch of tracheæ as seen through the body wall in the anterior end of a larva. Fig. 2. Tracheæ and organs in anterior part of body. Fig. 3. Tracheae to the ventral ganglionic mass. Fig. 4. Study of tracheæ in posterior end of body. al, alimentary tract, and tracheæ to alimentary tract; br, "brain"; Dt, dorsal tracheal trunk; fb, tracheæ to fat bodies; g, ventral ganglionic mass; $\mathrm{m}$, muscle layer; $\mathrm{ml}$, muscle crossing ventral tracheal tract; ph, pharynx; S?, position of anterior spiracle?; sg, salivary gland; tr, transverse trachea; ur, urinary tubule; $\mathrm{Vt}$, ventral longitudinal trunk; 1 ; trachea branching to gland, ganglia and fat bodies; 2 , trachea sending branches to urinary tubules. 
the third abdominal segment. It runs diagonally forward and inward, crossing the second abdominal segment on the outside of the muscle layer (m,m,m, fig. 3) and sends a branch toward the middle of the body at about the middle of this segment; then it continues across the first abdominal segment, in the body cavity, no longer attached to the body by muscles, and joins the side of the ganglionic mass.

In the specimen examined, the fourth abdominal segment contained on the right side the trachea running outside of the muscle layer, but none that ran forward to the ganglia. However, the corresponding trachea on the left side sent a long branch forward across the third, second and first abdominal segments, to the ganglia.

In the fifth segment a branch from the right ventral longitudinal trunk ran almost directly inward between the muscles and the body wall to nearly the mid ventral line of the body, where a long branch arose running forward, crossing the fourth, third, second and first abdominal segments, in the body cavity, to the ganglion. None was present on the left side. This alternating right and left supply of tracheae to the central nervous system merits further investigation.

The tracheae, which ran between the muscles and the body wall apparently are homologous with the ventral transverse branches found in the lepidopterous and trichopterous larvae. In the larva of Pyrausta nubilalis Hubn. these tracheae form a transverse connection between the spiracles, except in the first abdominal segment. In the larvae of the Hydropsychidae studied by me these tracheae form transverse connections in the thorax but not in the abdomen, and in Blepharipa, they apparently do not form transverse connections. Snodgrass (1924) does not mention ventral commissures in Rhagoletis; and Williams (1910) does not mention them in Cecidomyia, but his figure (5 Pl. 6) apparently shows one in the metathorax.

Tracher to the Alimentary Tract and Urinary Tubules.

The alimentary tract (al figs. 2, 4) is supplied, in the anterior part of the body by branches springing from the 
commissures between the dorsal and ventral longitudinal trunks near to the dorsal trunks (al fig. 2) ; the urinary tubules (ur fig. 4) are supplied in the same manner.

Arising from the stigmatic chamber, beside of the large dorsal trunk are several other tracheae. One of these runs forward and breaks up into many smaller branches which supply the alimentary tract and urinary vessels (to al and ur fig. 4). A branch arising from the dorsal trunk near to its junction with the stigmatic chamber also sends three good sized branches to the urinary tubules (2 fig. 4 ).

The Salivary Glands.

The salivary glands (sg fig. 2) are supplied with tracheae arising in a manner similar to those going to the alimentary tract.

\section{The Muscles.}

A study of figure 2 will make clear the supply of tracheae to the muscles much better than would a worded description.

\section{DisCUSSION}

The present study is necessarily incomplete, because of lack of material, and too superficial to allow of any but the most general conclusions to be drawn.

It does seem safe, however, to say that apparently the trichopterous, lepidopterous, and dipterous tracheal systems are variations of the same general scheme. This statement could not be made, however, were it not for the excellent works freely cited in the text.

The Trichoptera, as shown by Palmen (1877), possess rudimentary spiracles from which are developed the spiracles of the imago. In a study which I have made, but which has not been prepared for publication, I found that other than lacking functional spiracles, and possessing tracheal gills, the trichopterous larval tracheal system is very similar to that of the lepidopterous larva. The dipterous larval tracheal systems vary, as noted by Packard (1898), but here we have, in the Cecidomyiidae (Williams, 1910) open spiracles with a small ventral system, corresponding to the main longitudinal tracheae of the 
Lepidoptera and Trichoptera, with a large dorsal system corresponding to the small dorsal system of the Trichoptera. Should a study of the tracheal systems of the more generalized Diptera show them to possess a system yet more similar to that found in the Trichoptera, it might be possible to make a real homology of the various tracheal branches in the three orders. Blepharipa, and other muscoids, apparently have but carried the specialization shown in Cecidomyia a few steps farther, and not really departed from the general type.

DeGryse, J. J.

\section{Literature Cited.}

1926. The Morphogeny of Certain Types of Respiratory systems in Insect Larvae. Trans. Roy. Soc. Canada, 3rd Ser. Vol. XX, Sec. V, pp. 483-503. 3 pl.

Greene, C. T.

1921. An Illustrated Synopsis of the Puparia of 100 Muscoid Flies (Diptera). Proc. U. S. Nat. Mus. Vol. 60, Art. 10, pp. 1-39 pls. 1-20.

Packard, A. S.

1874. On the distribution and primitive number of spiracles in insects. American Nat. Vol. 8, pp. 531-534.

Packard, A. S.

1898. A Text Book of Entomology. MacMillian, New York. pp. v-729. 654 fig., $1 \mathrm{pl}$.

Palmen, J. A.

1877. Zur Morphologie des Tracheensystems. Helsingfors. pp. x-149. 2 pl.

Pratt, H. S.

1897. Imaginal Dises in Insects. Psyche. vol. 8, pp. 15-30. 11 figs.

Snodgrass, R. E.

1924. Anatomy and Metamorphosis of the Apple Maggot, Rhagoletis pomonella Walsh. Jour. Agric. Res. Vol. XXVIII, No. 1, pp. 1-36. 8 figs. 6 pls.

Williams, F. X.

1910. The Anatomy of the Larva of Cecidomyia resinicoloides Williams. Ann. Ent. Soc. America, vol. 3. pp. 45-57. pls. 6-8. 

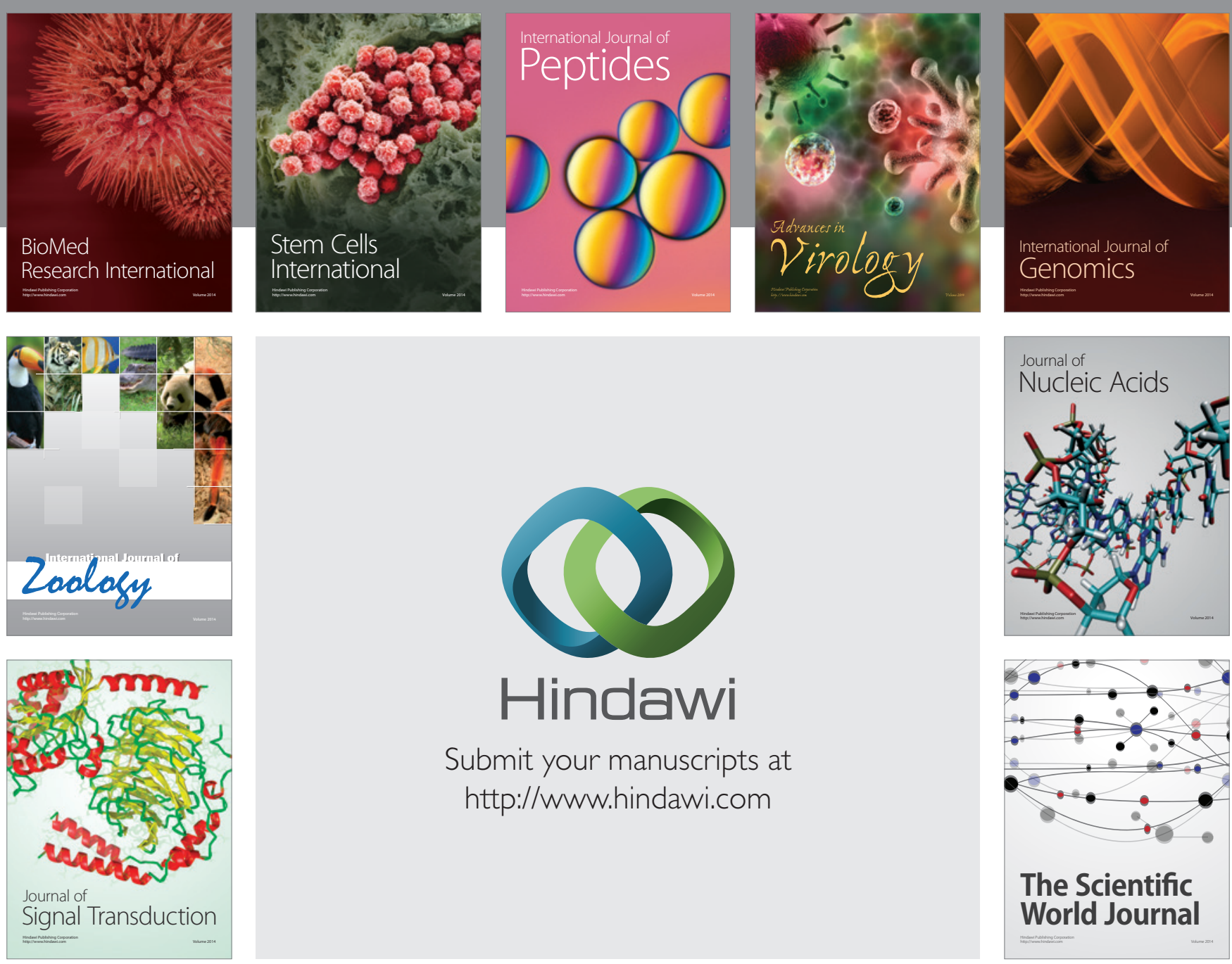

Submit your manuscripts at

http://www.hindawi.com
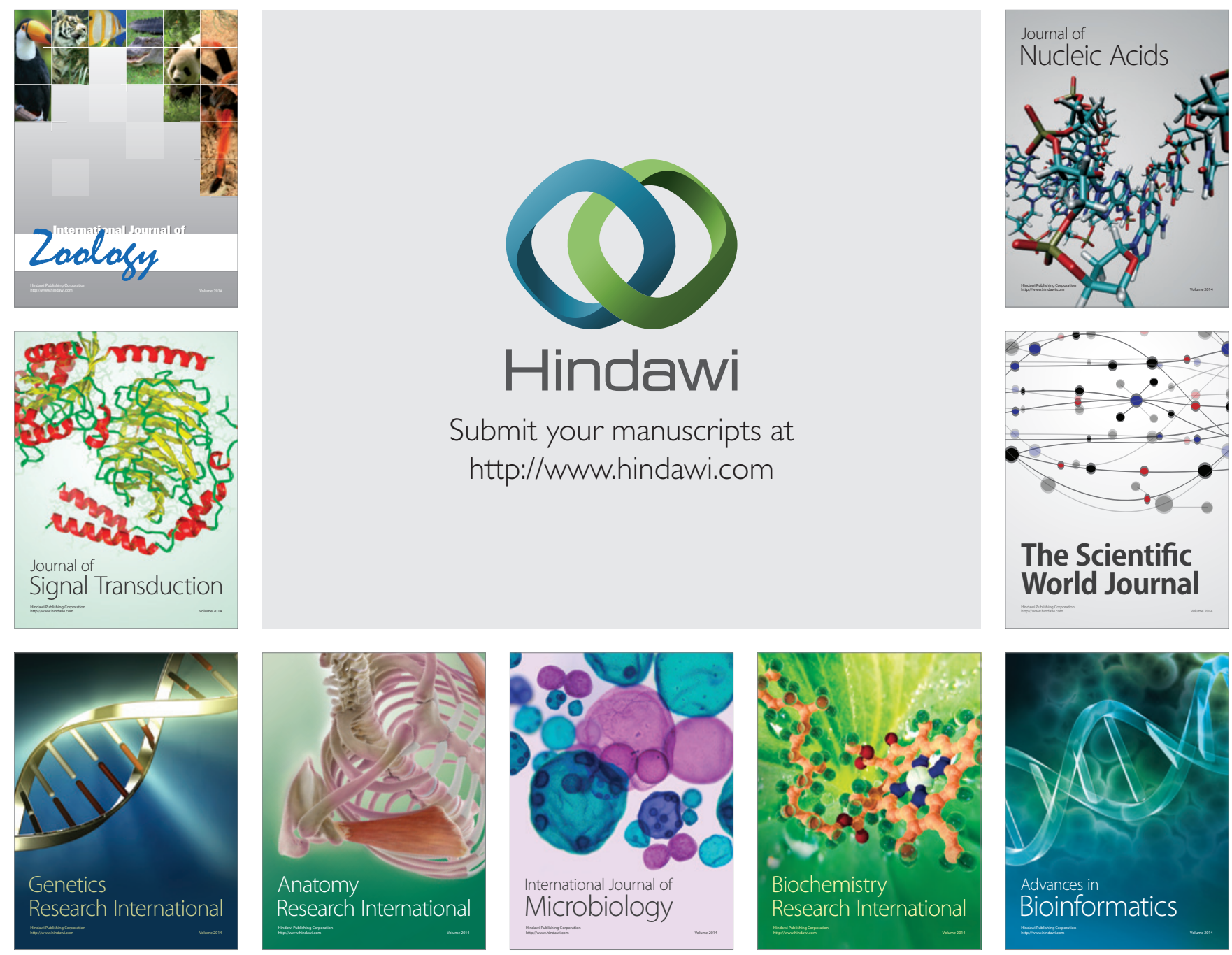

The Scientific World Journal
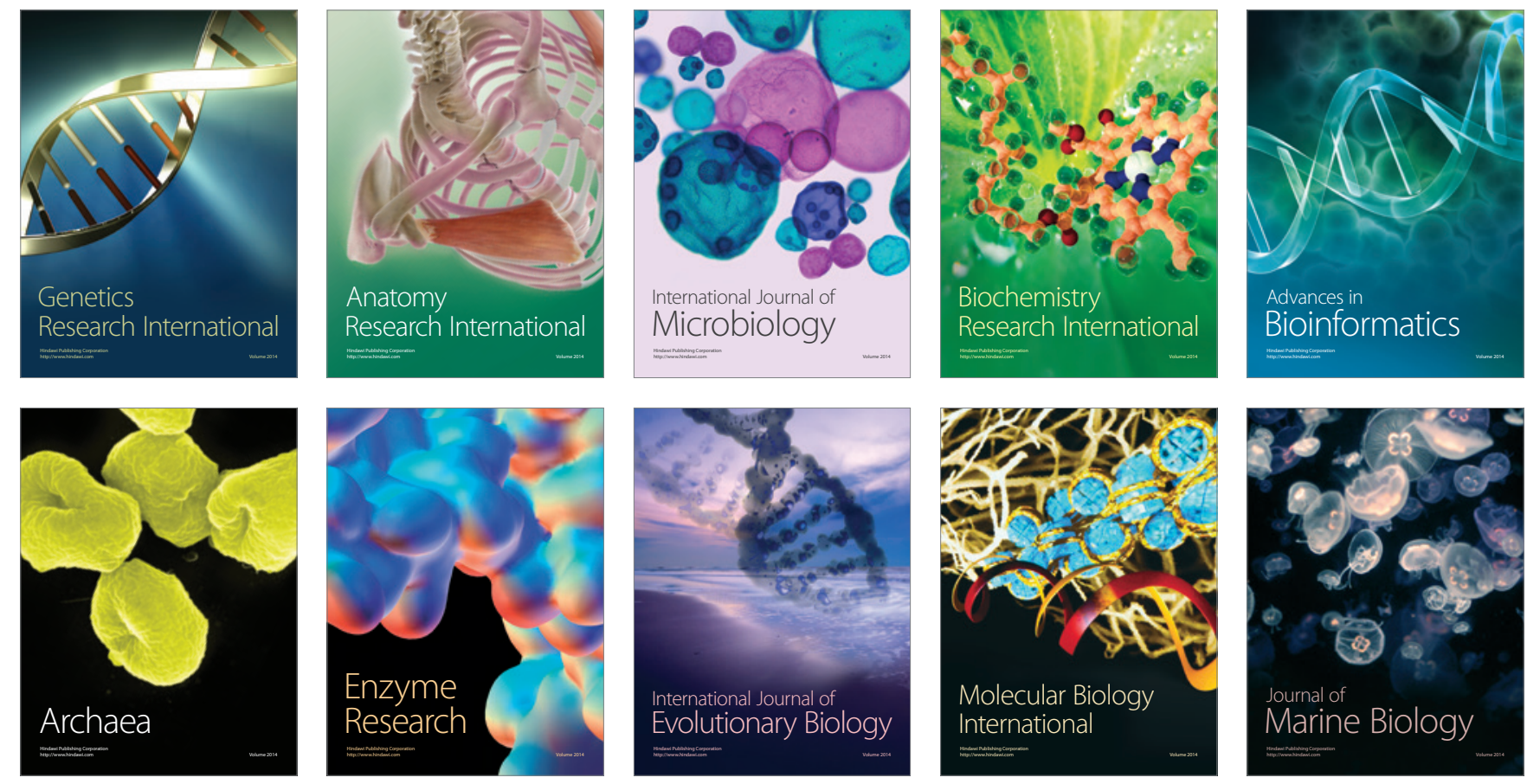